\title{
The Benefits of Integrated Methods in PV Making to Promote Their Efficiency and Achieve Low-Cost Modules
}

\author{
Salah A. Vaisi ${ }^{1,2}$ \\ ${ }^{1}$ Department of Architecture and Urban Planning, Faculty of Engineering, University of Kurdistan, Sanandaj, Iran; ${ }^{2}$ Bokan Center, \\ University of Applied Science and Technology, Bokan, Iran. \\ Email: svaisi@uok.ac.ir, vaisi2003@gmail.com
}

Received May $6^{\text {th }}, 2011$; revised September $24^{\text {th }}, 2011$; accepted October $3^{\text {rd }}, 2011$

\begin{abstract}
Active systems, such as solar thermal and photovoltaic offer a great potential in reducing of fuel energy consumption. To improve the sustainability of buildings, one of the challenges is to address the role of renewable energies. Today, the photovoltaic installations play an important role in creating solar renewable energy. They create $2000 \mathrm{MW}$ electrical energy per year and its annual global sales grown to approximately $5.6 \mathrm{GWp}$. This paper presents a general overview on a serious effort to produce PV panels that could provide cheaper solar power. It also focuses on short background of PV. Furthermore, thin film technology benefits, the method of the most absorbing of solar spectrum and the method of solar concentration and the advantages of these systems are presented. Ultimately, a new high concentration PV power system will be assessed.
\end{abstract}

Keywords: Photovoltaic; Renewable Energy; Energy Efficiency; Zero-Energy Building; Building Smart Materials

\section{Introduction}

Solar energy is free and inexhaustible. This vast, clean energy resource represents a viable alternative to the fossil fuels that currently pollute our air and water, threaten our public health, and contribute to global warming. Failing to take advantage of such a widely available and low-impact resource would be a grave injustice to our children and all future generations. In the broadest sense, solar energy supports all life on Earth and is the basis for almost every form of energy. The amount of energy from the sun that falls on Earth's surface is enormous. All the energy stored in Earth's reserves of coal, oil, and natural gas is matched by the energy from just 20 days of sunshine. Outside Earth's atmosphere, the sun's energy contains about 1300 watts per square meter. About one third of this light is reflected back into space, and some is absorbed by the atmosphere. By the time it reaches Earth's surface, the energy in sunlight has fallen to about 1000 watts per square meter at noon on a cloudless day. Averaged over the entire surface of the planet, 24 hours per day for a year, each square meter collects the approximate energy equivalent of almost a barrel of oil each year, or 4.2 kilowatt hour of energy every day. These figures represent the maximum available solar energy that can be captured and used, but solar collectors capture only a portion of this, depending on their efficiency. For example, a one square meter solar electric panel with an effi- ciency of 15 percent would produce about one kilowatthour of electricity per day in Arizona. In other words, if the efficiency of plants which capture and convert solar energy into the other forms of energy improves the lowcost and enough energy for all of the people will be accessible. By using some integrated methods the efficiency of solar photovoltaic cells could be promoted.

\section{Solar Thermal Concentrating Systems}

By using mirrors and lenses to concentrate the rays of the sun, solar thermal systems can produce very high temperatures as high as 3000 degree Celsius. This intense heat can be used in industrial applications or to produce electricity. Solar concentrators come in three main designs: parabolic troughs, parabolic dishes, and central receivers. The most common design is parabolic troughs, curved mirrors (Figures 1 and 2) that concentrate sunlight on a liquid inside a tube that runs parallel to the mirror. The liquid, at about 300 degree Celsius, runs to a central collector, where it produces steam that drives an electric turbine or convert to other forms of energy.

Parabolic dish concentrators are similar to trough concentrators, but focus the sunlight on a single point. Dishes can produce much higher temperatures, and so, in principle, should produce electricity more efficiently. But because they are more complicated, they have not succeeded outside of demonstration projects. A more prom- 


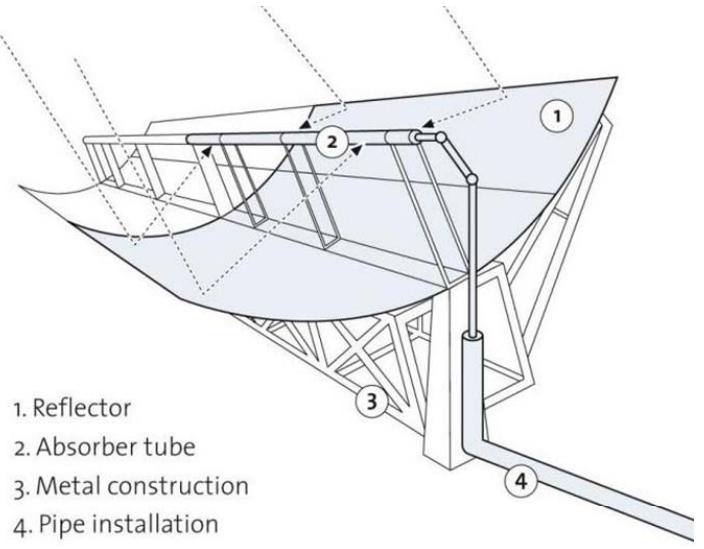

Figure 1. Parabolic trough concentrator.

ising variation of this method is Stirling Engine. Unlike a car's internal combustion engine, in which gasoline exploding inside the engine produces heat that causes the air inside the engine to expand and push out on the pistons, a Stirling Engine produces heat by way of mirrors that reflect sunlight on the outside of the engine. These dish-stirling generators produce about 30 kilowatts of power, and can be used to replace diesel generators in remote locations.

The third type of concentrator systems is a central receiver. One such plant in California features a "power tower" design in which a 17 -acre field of mirrors concentrates sunlight on the top of an 80-meter tower. The intense heat boils water, producing steam that drives a 10-megawatt generator at the base of the tower. The first version of this facility, Solar One, operated from 1982 to 1988 but had a number of problems. Reconfigured as Solar Two during the early to mid-1990s, the facility is successfully demonstrating the ability to collect and store solar energy efficiently [1]. Solar Two's success has opened the door for further development of this technology.

To date, the parabolic troughs have had the greatest commercial success of the three solar concentrator designs, in large part due to the nine Solar Electric Generating Stations (SEGS) built in California's Mojave Desert. Ranging from 14 to 80 megawatts and with a total capacity of 354 megawatts, each of these stations is still operating effectively [2]. Modified versions of the SEGS plants are being constructed in Arizona and Nevada. In addition, Stirling Energy Systems received approval from the California Public Utility Commission in October 2005 to build a 500-megawatt facility (with the option to add 350 megawatts) in the Mojave Desert using the parabolic dish design. Beginning in January 2009, the plant will supply power to Southern California Edison under a 20-year contract that will help the utility meet its requirements under the state's renewable electricity standard [3].

\section{An Overview on Photovoltaic}

In 1839, French scientist Edmund Becquerel discovered that certain materials would give off a spark of electricity when struck with sunlight. This photoelectric effect was used in primitive solar cells made of selenium in the late 1800s. In the 1950s, scientists at Bell Labs revised the technology by using silicon produced solar cells that could convert four percent of the sunlight energy directly into electricity. Within a few years, these photovoltaic (PV) cells were powering spaceships and satellites.

The most important components of a PV cell are two layers of semiconductor material generally composed of silicon crystals. On its own, crystallized silicon is not a very good conductor of electricity, but when impurities are intentionally added - a process called doping - the stage is set for creating an electric current. The bottom layer of the PV cell is usually doped with boron, which bonds with the silicon to facilitate a positive charge (P). The top layer is doped with phosphorus, which bonds with the silicon to facilitate a negative charge $(\mathrm{N})$. The

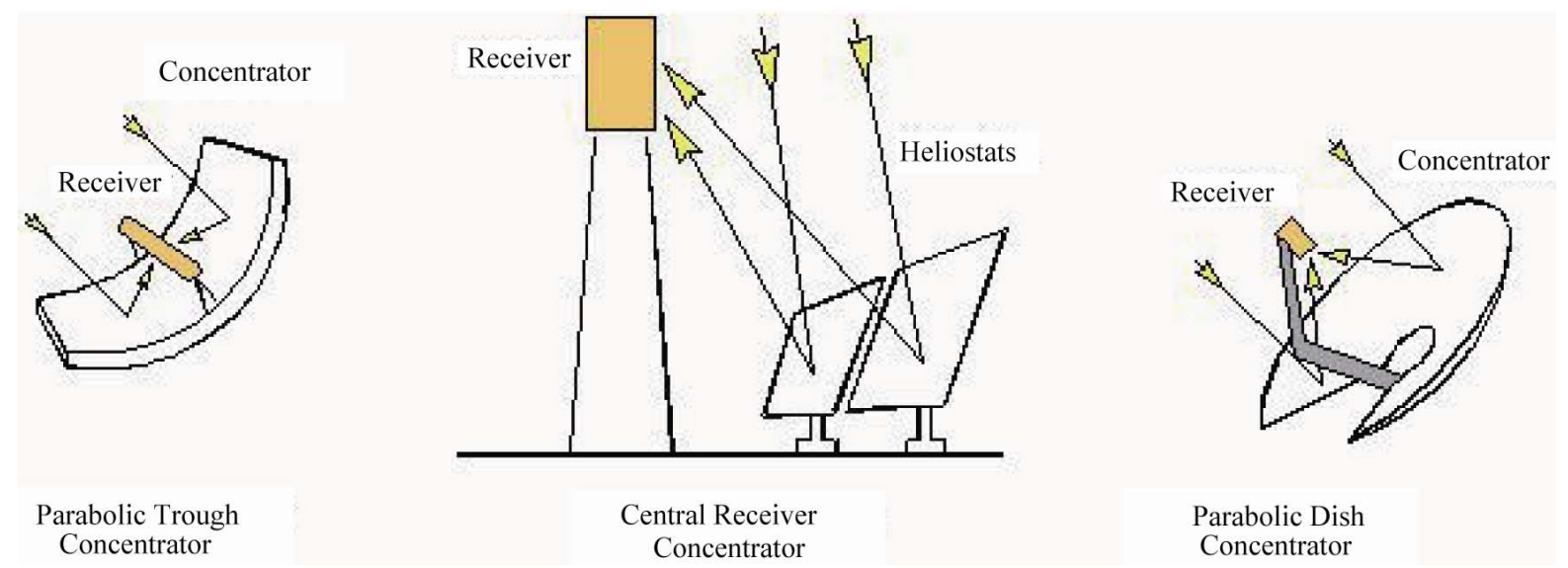

Figure 2. Three commonly used reflecting schemes for concentrating solar energy to attain high temperatures. 


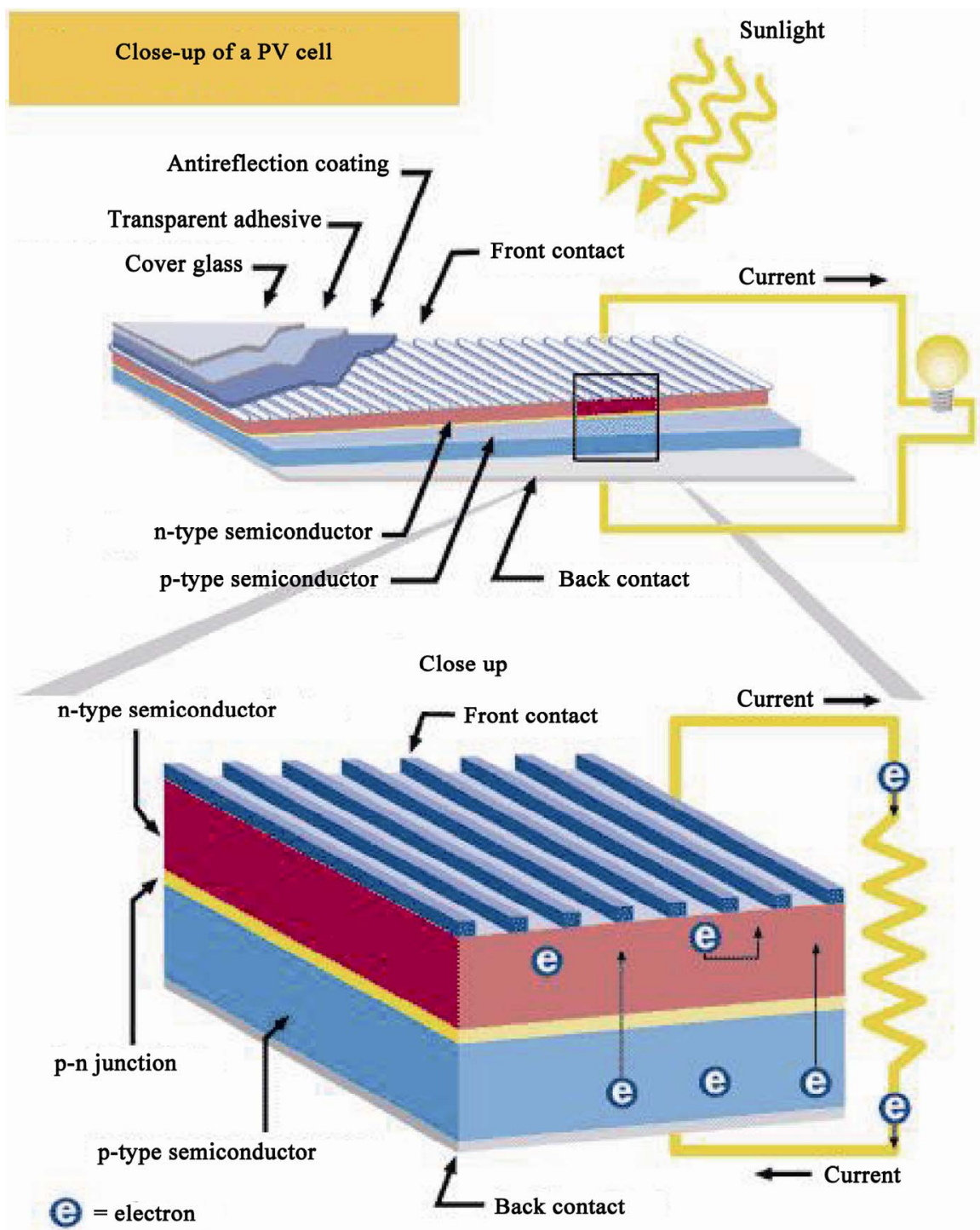

Figure 3. Close up of Photovoltaic cell.

surface between the resulting "p-type" and "n-type" semiconductors is called the P-N junction (Figure 3). Electron movement at this surface produces an electrical field that only allows electrons to flow from the p-type layer to the n-type layer.

When sunlight enters the cell, its energy knocks electrons loose in both layers. Because of the opposite charges of the layers, the electrons want to flow from the n-type layer to the p-type layer, but the electrical field at the P$\mathrm{N}$ junction prevents this from happening. The presence of an external circuit, however, provides the necessary path for electrons in the n-type layer to travel to the p-type layer. Extremely thin wires running along the top of the n-type layer provide this external circuit, and the electrons flowing through this circuit provide the cell's owner with a supply of electricity.

Most PV systems consist of individual square cells averaging about four inches on a side. Alone, each cell generates very little power (less than two watts), so they are often grouped together as modules. Modules can then be grouped into larger panels encased in glass or plastic to provide protection from the weather, and these panels, in turn, are either used as separate units or grouped into even larger arrays. The three basic types of solar cells made from silicon are single-crystal, polycrystalline, and amorphous which are described in the following:

- Single-crystal cells are made in long cylinders and sliced into round or hexagonal wafers. While this process is energy-intensive and wasteful of materials, it produces the highest-efficiency cells—as high as 25 percent in some laboratory tests. Because these highefficiency cells are more expensive, they are sometimes used in combination with concentrators such as mirrors or lenses. Concentrating systems can boost ef- 
ficiency to almost 40 percent. Single-crystal accounts for 29 percent of the global market for PV [4].

- Polycrystalline cells are made of molten silicon cast into ingots or drawn into sheets, then sliced into squares. While production costs are lower, the efficiency of the cells is lower too-around 15 percent. Because the cells are square, they can be packed more closely together. Polycrystalline cells make up 62 percent of the global PV market.

- Amorphous silicon (a-Si) is a radically different approach. Silicon is essentially sprayed onto a glass or metal surface in thin films, making the whole module in one step. This approach is by far the least expensive, but it results in very low efficiencies-only about five percent. Of course, to day the efficiency of this method is improved.

A number of exotic materials rather than silicon are under development, such as gallium arsenide (Ga-As), copper-indium-diselenide ( $\mathrm{CuInSe}_{2}$ ), and cadmium-telluride (CdTe). These materials offer higher efficiencies and other interesting properties, including the ability to manufacture amorphous cells that are sensitive to different parts of the light spectrum. By stacking cells into multiple layers, they can capture more of the available light. Although a-Si accounts for only five percent of the global market, it appears to be the most promising for future cost reductions and growth potential. In the 1970s, a serious effort began to produce PV panels that could provide cheaper solar power. Experimenting with new materials and production techniques, solar manufacturers cut costs for solar cells rapidly, as the following graph (Figure 4) shows. On the other hand, the number of direct and indirect jobs has been increased dramatically in recent years (Figure 5).

One approach to lowering the cost of solar electric power is to increase the efficiency of cells, producing more power per dollar. The opposite approach is to decrease production costs, using fewer dollars to produce the same amount of power. A third approach is lowering the costs of the rest of the system. For example, building-

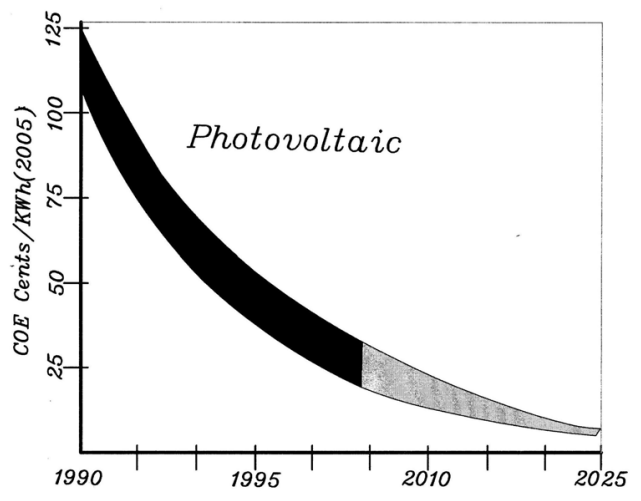

Figure 4. PV manufacturing cut cost.

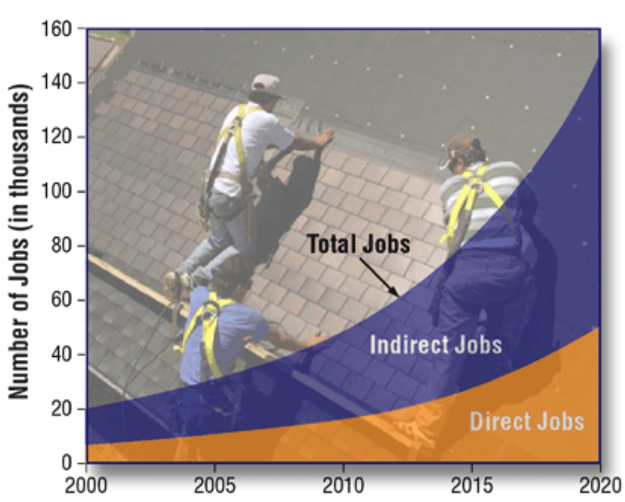

Figure 5. PV job creating.

integrated PV (BIPV) integrates solar panels into a building's structure and earns the developer a credit for reduced construction costs. Innovative processes and designs are continually reaching the market and helping drive down costs, including string ribbon cell production, photovoltaic roof tiles, and windows with a translucent film of a-Si. Economies of scale from a booming global PV market are also helping to reduce costs. More recently, thanks to lower costs, strong incentives, and net metering policies, the PV industry has placed more focus on home, business, and utility-scale systems that are attached to the power grid. In some locations, it is less expensive for utilities to install solar panels than to upgrade the transmission and distribution system to meet new electricity demand. In 2005, for the first time ever, the installation of PV systems connected to the electric grid outpaced off-grid PV systems in the United States [5]. As the PV market continues to expand, the trend toward grid-connected applications will be continuing. This distributed-generation approach provides a new model for the utilities of the future. Small generators, spread throughout a city and controlled by computers, could replace the large oil and nuclear plants that dominate the landscape now. Solar energy technologies are poised for significant growth in the 21 st century. More and more architects and contractors are recognizing the value of passive and active solar and learning how to effectively incorporate it into building designs. Solar hot water systems can compete economically with conventional systems in some areas. And as the cost of solar PV continues to decline, these systems will penetrate increasingly larger markets. In fact, the solar PV industry aims to provide half of all new U.S. electricity generation by 2025 [6].

\section{Three Methods Mostly Used to Promoted PV}

\subsection{Advanced Thin Film Technologies for Cost Effective Photovoltaics}

The overall challenge is to provide the scientific and 
technological basis for industrial mass production of cost-effective and highly efficient, environmentally sound and economically compliant large-area thin film solar cells and modules. By drawing on a broad basis of experience, the entire range of module fabrication and supporting will be covered: substrates, semiconductor and contact deposition, monolithic series interconnection, encapsulation, performance evaluation and applications by different factories. Photovoltaics have become an increasingly important industrial sector over the past ten years [7]. Therefore the main challenges are:

- Significantly reducing the cost/efficiency ratio towards $€ 0.5 / \mathrm{WP}$ in the long run.

- Providing the know-how and the scientific basis for large-area PV modules by identifying and testing new materials and technologies with maximum cost reduction.

- Developing the process know-how and the production technology, as well as the design and fabrication of specialized equipment, resulting in low costs and high yield in the production of large area thin film modules.

To meet these challenges, existing concepts for materials and technology will be improved and brought to maturity in close cooperation with industry, and new options will be investigated for materials and new types of solar cells to provide the scientific and technological basis for the next generation of PV devices. Accordingly, the research activities range from basic research to industrial implementation [7].

The state-of-the-art for advanced thin film PV technology and the enhancement within the proposed project

\section{is summarized in Table 1.}

Prototypes of a small junction box especially suited for thin-film modules were developed. Limiting the by-pass diodes to only one per box allows a reduction in both size and cost. It is also possible to use the box for parallel inter-connection of the modules.

\subsection{Towards the Production of Cost-Competitive Photovoltaic Solar Energy by Absorbing the Most of the Solar Spectrum}

Solar radiation is a significant energy source: only approximately 1000 Joules of energy per second per square meter are accessible. It is clear to us that strategies to reach the ultimate goal of a module cost of $€ 1 / \mathrm{Wp}$ will necessarily have to go through the development of concepts capable of extracting the most of every single photon available. In this respect, each of the three activities envisaged in this paper to achieve the general goal has to confront its own challenges. The multi-junction activity pursues the development of solar cells that approach $40 \%$ efficiency. To achieve this, it faces the challenge of finding materials with a good compromise between lattice matching and band-gap energy. The thermo photovoltaic activity bases part of its success on finding suitable emitters that can operate at high temperatures and/or adapt their emission spectra to the cell's gap. The other part relies on the successful recycling of photons so that those that cannot be used effectively by the solar cells can return to the emitter to assist in keeping it hot. The intermediate-band solar cell approach addresses the challenge of proving a principle of operation which would see a

Table 1. Expected enhancement of the state-of-the-art.

\begin{tabular}{|c|c|c|c|}
\hline Technology & State-of-the-art & Substrate, process (efficiencies) & Planned enhancement in IP (for Europe) \\
\hline \multicolumn{4}{|c|}{ Lab cells } \\
\hline $\mathrm{a}-\mathrm{Si} / \mu \mathrm{c}-\mathrm{Si}$ & $\begin{array}{l}12 \% \text { (Kaneka) } \\
11 \% \text { (UniNE, FZJ }\end{array}$ & On glass, $\mathrm{PE}-\mathrm{CVD}$ & $14 \%$ \\
\hline Poly Si & $9 \%$ (Sanyo) & On metal substrate, $\mathrm{SPC}$ & $15 \%$ on foreign substrates \\
\hline CIGS low gap & $\begin{array}{l}19.2 \% \text { (NREL) } \\
16 \%-17 \% \text { (NREL) }\end{array}$ & $\begin{array}{l}\text { On glass, co-evaporation } \\
\text { On metal foil, co evaporation }\end{array}$ & $\begin{array}{l}18 \% \text { on metal foil } \\
9 \% \text { on polyimide foil }\end{array}$ \\
\hline CIGS wide gap & $12 \%-13 \%(\mathrm{HMI})$ & On glass, sputtering, $\mathrm{PVD}$ & $\begin{array}{l}13 \% \text { - 14\%, advanced equipment. } 10 \% @ 60 \% \text { IR transparency for } \\
\text { tandem applications }\end{array}$ \\
\hline CIGS tandem & 7\% (HMI) & On glass, co-evaporation & $15 \%$ \\
\hline \multicolumn{4}{|c|}{ Prototypes, pilot production } \\
\hline $\mathrm{a}-\mathrm{Si} / \mu \mathrm{c}-\mathrm{Si}$ & $10 \%$ (Kaneka, FZJ) & $\begin{array}{l}\text { On glass } 30 \times 30 \mathrm{~cm}^{2}(\mathrm{FZJ}) \\
\text { On glass } 3738 \mathrm{~cm}^{2}(\text { Kaneka })\end{array}$ & $\begin{array}{l}\text { Equipment for cost-effective production of } 10 \% \text { modules }\left(1 \mathrm{~m}^{2} @\right. \\
\text { costs towards } € 0.5 / \mathrm{Wp})\end{array}$ \\
\hline CIGS wide gap & $10 \%$ (Sulfurcell) & On glass $5 \times 5 \mathrm{~cm}^{2}$, sputtering, PVD & $10 \%$ on $125 \times 65 \mathrm{~cm}^{2}$ \\
\hline \multicolumn{4}{|c|}{ Commercial product } \\
\hline $\mathrm{a}-\mathrm{Si}$ & $\begin{array}{l}6 \%-7 \% \text { (Unisolar, } \\
\text { SCHOTT, Kaneka, ...) }\end{array}$ & On glass, PE-CVD & \\
\hline CIGS low gap & $10 \%$ (Shell, Würth) & On glass, co-evaporation & $11 \%-12 \%$, cost-effectiveness, environmentally sound \\
\hline
\end{tabular}


significant improvement in the performance of the cells.

In a Project which coordinated by Prof. Antonio Luque et al. the activity devoted to the search for new molecules engenders the challenge of identifying molecules capable of undergoing two-photon processes: that is molecules that can absorb two low-energy photons to produced a high-energy excited state or, for example, dyes that can absorb one high-energy photon and re-emit its energy in the form of two photons of lower energy. Among all of the above concepts, the multi-junction approach appears to be the most readily available for commercialization. For that, the activity devoted specifically to speeding up its path to market is the development of trackers, optics and manufacturing techniques that can integrate these cells into commercial concentrator systems ${ }^{1}$.

The multi-junction solar cell approach pursues the better use of the solar spectrum by using a stack of single-gap solar cells incorporated in a concentrator system, in order to make the approach cost-effective (Figure 6). The project, at its outset, aimed at cells with an efficiency of $35 \%$. This result has already been achieved by FhG-ISE in the second year of their project and their consortium now aims to achieve efficiencies as close as possible to $40 \%$. In the thermo-photovoltaic approach the sun heats up, through a concentrator system, a material called the 'emitter', leading to incandescence (Figure 7). The radiation from this emitter drives an array of solar cells, thus producing electricity. The advantage of this approach is that, by an appropriate system of filters and back-reflectors, photons with energy above and below the solar cell band-gap can be directed back to the emitter, helping to keep it hot by recycling the energy of

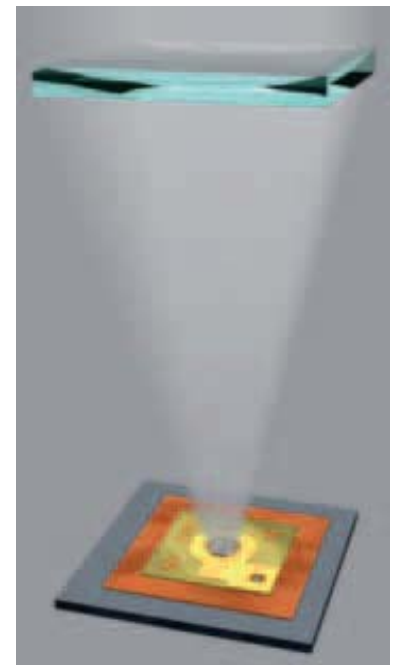

Figure 6. Schematic illustrating the operation of a multijunction solar cell in a concentrator system.

${ }^{1}$ The Project is coordinated by Professor Antonio Luque Instituto de Energía Solar assisted by Projektgesellschaft Solare Energiesysteme $\mathrm{GmbH}$ (PSE).

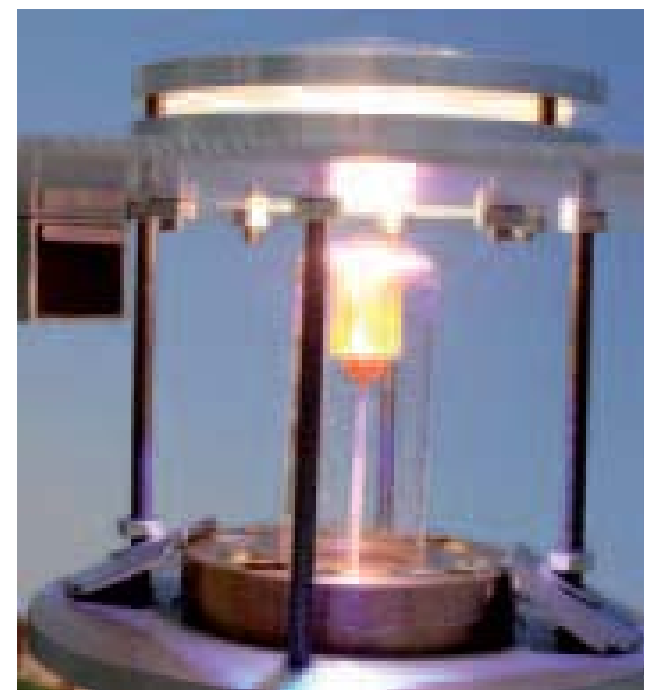

Figure 7. Emitter heated up by the sun through a concentrator system.

these photons that otherwise would not be converted optimally by the solar cells. By the conclusion, it is expected that the system, made up basically of the concentrator, emitter and solar cell array can be integrated and evaluated. The "intermediate-band" approach pursues better exploitation of the solar spectrum by using intermediate-band materials. These materials are characterized by the existence of an electronic energy band within what otherwise would be a conventional semiconductor band-gap. According to the principles of operation of this cell, the intermediate band allows the absorption of low band-gap energy photons and the sub sequent production of enhanced photocurrent without voltage degradation. This method also expects to identify as many intermediate-band material candidates as possible, as well as demonstrate experimentally the operating principles of the intermediate-band solar cell by using quantum dot solar cells as workbenches.

\subsection{High Concentration PV Power System (HICONPV)}

Existing and innovative solar concentrators were evaluated for their properties in high-concentration photovoltaics. Plant types were identified that fulfill the technical requirements of homogenous irradiation distribution with solar concentration factors of 500 to 2000 suns and costeffective implementation perspectives. The conclusions were that Modified Spherical Dish (Tailored Concentrator, Figure 8) configurations look more suitable for meeting current technology requirements than classical Parabolic Dish solutions. The results shown with this design are promising. It has been proposed to build and test a tailored concentrator for HICONPV technology with this design. 


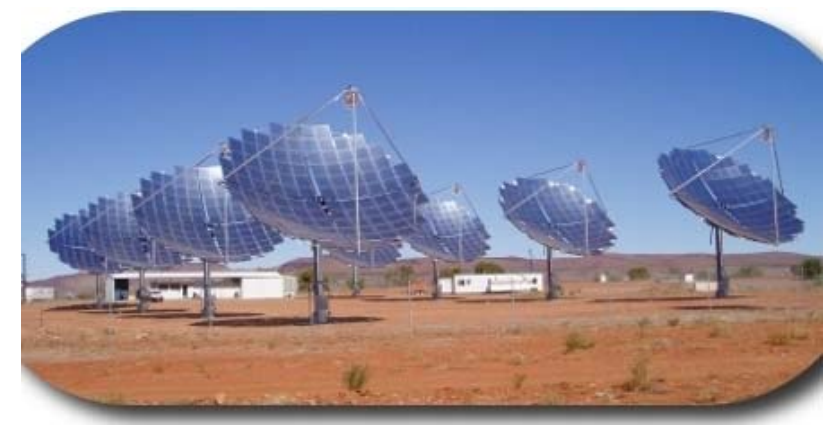

Figure 8. Tailored concentrator.

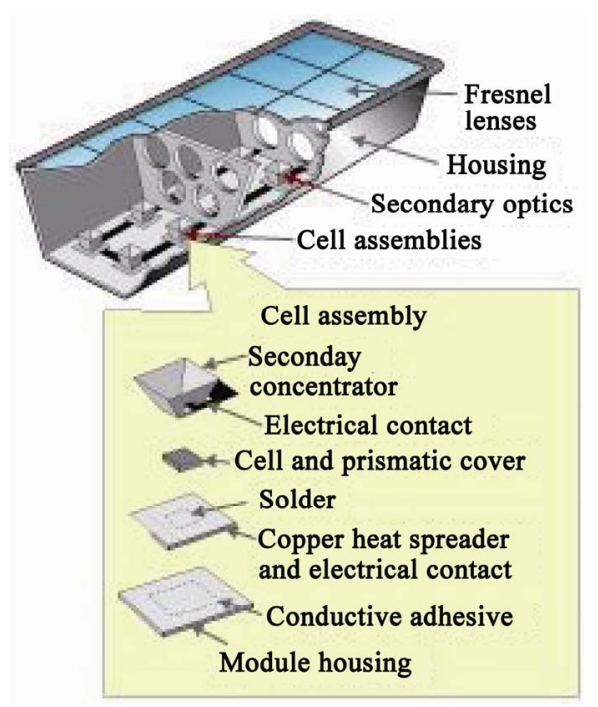

Figure 9. Layout of a solar concentrator.

An innovative heliostat variant was evaluated for its properties in high-concentration photovoltaics, demonstrating that the proposed Torque Tube Heliostat design concept promises significant cost advantages over existing heliostat designs. This can be achieved with a much lower construction height of the TTH, which reduces drastically the wind loads on the structure and the required specific drive power. The aim of this tailor concentrator is to prove the real possibilities of this innovative conceptual design, and to see the performance of the concept under real manufacturing constraints. The proposed final configuration was not optimized for $1000 \mathrm{x}$ (X equals approximately the area of the optic collector divided by area of the semiconductor solar cell. ZenithSolar system is designed to a concentration factor of $1000_{\mathrm{X}}$ ), but rather close, so it is necessary to take into account the optimized structural heliostat concept, where the shape of the concentrator is no longer round but rectangular. Rectangular concentrators allow us to keep the gravity centre lower for the same aperture area (Figure 9). This has a strong influence on the structural design and the final $\operatorname{cost}^{2}$. In conventional CPV systems, the excess heat generated in the solar cell needs to be removed to avoid damaging the cell and to maintain high efficiency of electricity conversion. ZenithSolar utilizes the heat generated at the solar cell receiver to provide usable hot water heating, improving overall solar power conversion efficiency to $75 \%$.

\section{Expected Results}

The concept of this research project focuses specially on:

- New monolithic integrated modules with efficiencies of $20 \%$ and above.

- Module design for irradiation up to 1000 suns.

- Adaptation of already proven concentrator's concepts that promise high quality and high reliability.

\section{REFERENCES}

[1] Concentrating Solar Power Program, "Solar Two Demonstrates Clean Power for the Future," 2000. http://www.energylan.sandia.gov/sunlab/files/stfuture.pdf

[2] Solar Energy Technologies Program, "Solar Energy Technologies Program: Multi-Year Program Plan 2001-2011," 2006.

http://www1.eere.energy.gov/solar/pdfs/set_myp_2007-2 011_proof 1.pdf

[3] Renewable Energy Access, "World's Largest Solar Project Unveiled," 2005.

http://www.renewableenergyaccess.com/rea/news/story?i $\mathrm{d}=35263$

[4] Solar Energy Technologies Program, "Solar Energy Technologies Program: Multi-Year Program Plan 2001-2011," 2006.

http://www1.eere.energy.gov/solar/pdfs/set_myp_2007-2 011_proof 1.pdf

[5] The Prometheus Institute, "U.S. Market Analysis," PV News, Vol. 25, No. 5, 2006, pp. 4-5.

[6] Solar Energy Industries Association, “Our Solar Power Future: The US Photovoltaics Industry Roadmap through 2030 and beyond," 2004. http://www.seia.org

[7] Renewable Energy Technologies, "Long Term Research in the 6th Framework Programme," European Commission, Directorate-General for Research, Directorate Energy, Brussels, 2007. 